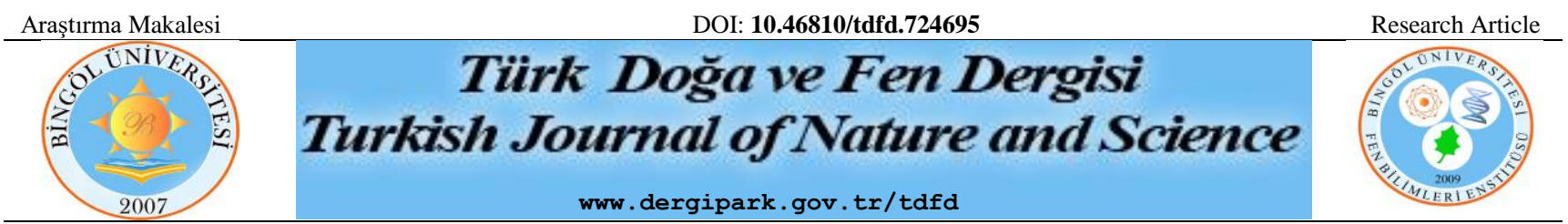

\title{
İstanbul'daki Tahıl Unlarında Aflatoksin, Deoksinivalenol ve Zearalanon Düzeyleri
}

\author{
Kadriye TÜRKEŞSİZ* ${ }^{1}$, Kâmil BOSTAN ${ }^{2}$ \\ ${ }^{1}$ Haliç Üniversitesi, Meslek Yüksekokulu Aşçılık Programı, İstanbul, Türkiye \\ ${ }^{2}$ İstanbul Aydın Üniversitesi, Güzel Sanatlar Fakültesi, Gastronomi ve Mutfak Sanatları Bölümü, İstanbul, Türkiye \\ Kadriye TÜRKEŞSIZ ORCID No: 0000-0003-3028-2291 \\ Kâmil BOSTAN ORCID No: 0000-0001-7583-0066
}

*Sorumlu yazar: kadriyeturkessiz@halic.edu.tr

(Alınış: 21.04.2020, Kabul: 05.06.2020, Online Yayınlanma: 18.06.2020)

Anahtar
Kelimeler
Tahil unu,
Küf,
Aflatoksin,
Deoksinivalenol,
Zearalanon,
LC-MS/MS

Anahtar

Kelimeler

Tahil unu,

Küf,

LC-MS/MS
Öz: $\mathrm{Bu}$ çalışma bazı tahıl unlarında küf düzeyini ve bazı mikotoksinlerin [aflatoksin, deoksinivalenol ve zearalanon] varlığını araştırmak amacıyla gerçekleştirilmiştir. Bu amaçla 2015 yılında İstanbul ilinde bulunan çeşitli firın ve marketlerden 112 tane farklı un [25 tane tam buğday unu, 29 tane beyaz un, 30 tane çavdar unu ve 28 tane kepek] örneği toplanmıştır. Toplanan örneklerde ilk olarak direk ekim ve seyreltme yöntemleri ile küf sayımı yapılmıştır. Devamında aflatoksin, deoksinivalenol ve zearalanon düzeyleri LC-MS/MS cihazı kullanılarak belirlenmiştir. İncelenen tahıl un örneklerinin tümü Türk Gıda Kodeksi'[TGK] nin belirlediği maksimum sınır değerinin $\left[\begin{array}{lll}10^{4} & \mathrm{kob} \mathrm{g}^{-1}\end{array}\right]$ altında küf içerdiği saptanmıştır. Un örneklerinin 9'unda $0,17-5.95 \pm 0,002 \mu \mathrm{g} \mathrm{kg}^{-1}$ arasında aflatoksin, 41'inde 0,06-70,04 $\pm 0,0032 \mu \mathrm{g} \mathrm{kg}^{-1}$ arasında deoksinivalenol [DON] ve 15 'inde $0,04-3,04 \pm 0,0018 \mu \mathrm{g} \mathrm{kg}^{-1}$ arasında zearalanon [ZON] miktarı tespit edilmiştir. Örneklerin tümünde deoksinivalenol ve zearalanon düzeyi TGK' nin belirlediği kabul edilebilir sınırların altında bulunmuştur. Analiz edilen örneklerden sadece bir un örneğinde [çavdar] aflatoksin $\mathrm{B} 1+\mathrm{B} 2+\mathrm{G} 1+\mathrm{G} 2$ düzeyi $\left[5,95 \mu \mathrm{g} \mathrm{kg}^{-1}\right.$ ] limit değerin [4 $\mu \mathrm{g} \mathrm{kg}^{-1}$ ] üzerinde saptanmıştır. Elde edilen bulgulara göre İstanbul'da satışa sunulan unların küf içeriğinin kabul edilebilir sınırlar içinde olduğu ve örneklerdeki mikotoksin düzeyi bir örnek dışında tüm örneklerde kabul edilebilir limitlerin altında olduğu sonucuna varılmıştır. Gıda zinciri boyunca küf ve mikotoksin kaynaklı kontaminasyonun engellenmesi hem gıda kalitesinin sağlanmasında hem de tüketicilerde oluşabilecek sağlık risklerinin önlenmesinde büyük önem taşımaktadır.

\section{Aflatoxin, Deoxynivalenol and Zearalenone Levels in Grain Flour Samples in İstanbul}

\section{Keywords}

Grain flour, Mold,

Aflatoxin, Deoxynvalenol, Zearalanon, LC-MS/MS

\begin{abstract}
This study was carried out to investigate the level of mold in some kinds of grain flour and the presence of some mycotoxins [aflatoxin, deoxynvalenol and zearalanon]. For this purpose, in 2015, 112 different types of flour [25 samples of whole wheat flour, 29 samples of white flour, 30 samples of rye flour and 28 samples of wholemeal] were collected from various bakeries and markets in İstanbul. In the collected samples, firstly, mold counting was done by direct sowing and dilution methods. Subsequently, aflatoxin, deoxynvalenol and zearalanone levels were determined using LC-MS/MS devicce. It has been determined that all of the grain flour samples analyzed contain mold below the maximum limit value $\left[10^{4} \mathrm{cfu} \mathrm{g}^{-1}\right]$ determined by the Turkish Food Codex. The amount of aflatoxin $0,17-5,95 \mu \mathrm{g} \mathrm{kg}^{-1}$ in 9 of flour samples, deoxynvalenol between $0,06-70,04 \mu \mathrm{g} \mathrm{kg}^{-1}$ in 41 of flour samples and zearalanone between $0,04-$ $3,04 \mu \mathrm{g} \mathrm{kg}^{-1}$ in 15 of flour samples. In all of the samples, deoxynvalenol and zearalanone levels were found below the acceptable limits determined by TGK. In only one flour sample from the analyzed samples [rye] aflatoxin B1 + B2 + G1 + G2 level [5.95 $\mu \mathrm{g} \mathrm{kg}^{-1}$ ] was detected above the limit value $\left[4 \mu \mathrm{g} \mathrm{kg}^{-1}\right.$ ]. According to the findings, it was concluded that the mold content of the flours offered for sale in Istanbul is within acceptable limits and the mycotoxin level in the samples is below the acceptable limits in all samples except one sample, Preventing mold and mycotoxin-induced contamination throughout the food chain is of great importance both in ensuring food quality and in preventing health risks that may occur in consumers
\end{abstract}




\section{GİRiş}

Mikotoksinler, bazı filamentli mantarlar [küfler] tarafından üretilen toksik sekonder metabolitlerdir. Düşük moleküler ağırlıklı bileşikler olup [genellikle 1000 Dalton'dan az] doğal olarak oluşurlar. Besin zincirimizde bitkisel bazlı besinlerin mikotoksinlerle kontamine olmasıyla ya da gıda üzerinde toksijenik küflerin gelişimiyle oluşmaktadır. Mikotoksinler mısır, tahıl, soya fasulyesi, sorgum, yer fistığı gibi gida ve yem bitkilerinde tarlada, olgunlaşma esnasında ve nakliye sırasında oluşabilmektedir. Mikotoksinle kontamine olmuş gıda veya yemin tüketilmesiyle insanlarda ve hayvanlarda akut veya kronik toksisiteye neden olabilir. Mikotoksinle kontamine olmuş g1da ve yemlerin doğrudan tüketiminden kaynaklanan olumsuz etkilere ilişkin kaygıların yanı sıra, potansiyel mikotoksin kalıntıları veya metabolitleri içeren et, süt ve yumurta gibi hayvansal kaynaklı gıda ürünlerinin tüketilmesiyle ilgili halk sağlığı endişesi de vardır [1].

Üç fungal cins, Aspergillus, Fusarium ve Penicillium üyeleri, başlıca mikotoksin üreticileridir. Bugüne kadar 300'den fazla mikotoksin tanımlanmış, bunlardan 6's1 [aflatoksin, trikotesen, zearalanon, fumonisin, okratoksin ve patulin] gidalarda yaygın olarak bulunurlar [1]. Mikotoksinler, gıda güvenliği ve insan sağlığı açısından hem Türkiye'de hem de Dünya çapında ciddi sorunlara yol açmaktadır [2, 3].

Tahıllar ülkemizde binlerce yıldır yetiştirilmekte ve kırsal alanlarda yaşamın bir parçasıdır. Buğday, arpa, mısır, yulaf, çavdar, pirinç, darı, kılçıksız buğday, kanarya otu ve karışık hububat Türkiye'de yetiştirilen temel tahıl çeşitleridir [4]. Ülkemizde tahıl ve tahıldan elde edilen ürünler insan ve hayvan beslenmesinde önemli bir yere sahiptir. Yetişkin bir Türk'ün günlük ortalama buğday ve ögütülmüş buğday ürünlerinin tüketimi çoğu Batı ülkesinden iki kat daha fazladır ve bu miktar günlük diyetin yaklaşık \%50'sine karş1lık gelmektedir [5]. Dünya'da kişi başına günlük ekmek tüketimi; İspanya'da $112 \mathrm{~g}$, İngiltere'de $72 \mathrm{~g}$, İsviçre'de 130 g, İran'da 300 g ve Türkiye'de bu değer 195 g'dır [6]. Tahıl taneleri hasat, taşıma, depolama ve işleme süreçlerinde sıklıkla mantarlar tarafından üretilen mikotoksin kontaminasyon riski taşımakta ve bu süreçlerde oluşan toksinlerin canlılarda alerjik ve toksijenik reaksiyonlara sebep olmaktadır $[2,3,7,8]$. Geçmiş yıllarda yapılan çalışmalarda ülkemizde üretilen un ve unlu mamullerde küf kontaminasyonuna ve mikotoksin içeriğine dikkat çekilmiş, halk sağllğ 1 açısından oluşturacağ $\breve{1}_{1}$ riskleri vurgulanmıştır $[4$, $9,10,11]$.

$\mathrm{Bu}$ çalışma tam buğday unu, beyaz un, çavdar unu ve kepekte küf ve mikotoksin [aflatoksin, deoksinivalenol ve zearalanon] varlığını belirlemek amacıyla gerçekleştirilmiştir.

\section{MATERYAL VE METOT}

Örnekler 2015 yılının Ağustos, Eylül, Ekim, Kasım aylarında İstanbul ilindeki farklı firın ve marketlerden 25 tam buğday unu, 29 beyaz un, 30 çavdar unu ve 28 kepek olmak üzere 112 farklı örnek tedarik edilmiştir. Birer kilogram temin edilen her örnek 7 gün içinde analize alınmış ve bu süreçte $+4{ }^{\circ} \mathrm{C}^{\prime}$ [Arçelik buzdolabı] de saklanmıştır.

\subsection{Küf ve Maya Sayımı}

Tahıl unu örneklerinden $10 \mathrm{~g}$ alınarak $90 \mathrm{ml}$ steril peptonlu [ISO LAB 204] su içine aktarılmıştır. Homojenizasyon için stomocher' [Aes Chemunex] da 2 dakika kadar orta hizda tutulmuştur. Homojenizasyon işleminden sonra içlerinde 9'ar ml steril peptonlu su bulunan tüplere $1 \mathrm{ml}$ örnek eklenerek seri dilüsyonlar hazırlanmıştır. Steril kabinde seyreltmelerden çift paralel olacak şekilde içinde YGC (Yeast Glucose Chloramphenicol) [Merck 1.16000.0500] bulunan petri kutularına tüplerdeki örnek dilüsyonlarından $1 \mathrm{ml}$ inoküle edilmiştir. Ekim yapılan petriler $25^{\circ} \mathrm{C}$ 'de 5 gün inkübasyona [Binder BD260] bırakılmıştır. İnkübasyon sonrası besi yerinde gelişen kolonilerin sayımı yapılmıştır [12].

\subsection{Mikotoksin Analizleri}

\subsubsection{Numune hazırlama ve temizleme prosedürleri}

Homojen edilmiş örnekten 25 gr tartılmıştır. Üzerine 50 $\mathrm{ml}$ ekstraksiyon [\%80 metanol+ $\% 20$ asetik asit] eklenmiş ve 30 dakika karıştırılmıştır. 10 dakika santrifüj edilmiştir. Berrak sıvı $0,45 \mu \mathrm{m}$ enjektör filtresinden geçirilmiştir. 1/1 oranında seyreltme sıvıs1 [\%20 metanol $+\% 2$ asetik asit $+\% 78$ su] ile seyreltilmiştir. Ekstrakt LC-MS/MS sistemine $10 \mu$ l enjeksiyon edilmiştir [13].

\subsubsection{Analiz}

Un örneklerindeki mikotoksin [aflatoksin, deoksinivalenol, zearalanon] seviyeleri LC-MS/MS multi mikotoksin yöntemi ile belirlenmiştir. Analiz LCMS/MS [Agilent 6460 QQQ] cihazında, Mobil Faz A [su, \%0,1'lik formikasit, $2 \mathrm{mM}$ amonyum format], Mobil Faz B [metanol, \%0,1'lik formikasit, $2 \mathrm{mM}$ amonyum format], Shim-pack XR-ODS II 3,0 mm I.D. x $75 \mathrm{~mm}$ kolon, nebulize edici basınc 40 psi, kolon firını $45{ }^{\circ} \mathrm{C}$, kurutma sıcaklığ $400{ }^{\circ} \mathrm{C}$, akış hızı $0,5 \mathrm{ml} / \mathrm{dk}$. ve 10 dakika tarama süresi şartlarıyla gerçekleştirilmiştir. Validasyon parametreleri yöntem validasyonu için performans kriteri olarak kullanılmıştır [14]. Mikotoksin içermeyen numune [blank] kullanılarak tespit limiti [LOD], tayin limiti [LOQ] ve tekrarlana bilirlik [\%RSD] değerleri Tablo 1'deki gibi belirlenmiştir.

Analizlerde yüksek saflıkta Sigma Aldrich marka toksin standartlar1 [AFB1 1162-65-8], [AFB2 7220-81-7], [AFG1 1165-39-5], [AFG2 7241-98-7], [DON 5148110-8], [ZON 17924-92-4], asetonitril [Sigma Aldrich 
21004 75-05-8], metanol [Merck 1098229 67-56-1], amonyum format [Sigma Aldrich 516961 540-69-2], formik asit [Sigma Aldrich 695076 64-18-6], asetik asit [Sigma Aldrich 695092 64-19-7] kullanılmıştır. Öncelikle, farkl 1 konsantrasyonlarda standart stok çözeltiler Tablo 2'deki gibi hazırlanmıştır. Standart çözeltilerde [asetonitril: su] [50: 50] oranında karışım kullanılarak gerekli seyreltmeler yapılmıştır. Bu stok çözeltiler daha sonra Tablo 3'deki matris etkili kalibrasyon standartlarını oluşturmak için kullanılmıştır.

Tablo 1. LC-MS / MS yönteminde tespit ve tayin limiti

\begin{tabular}{|l|l|l|l|l|}
\hline $\begin{array}{l}\text { Mikotoksin } \\
\text { tipi }\end{array}$ & $\%[$ RSD] & LOD [ppb] & LOQ [ppb] \\
\hline AFB1 & 6,52 & & 0,10 & 0,33 \\
\hline AFB2 & 5,79 & 0,10 & 0,34 \\
\hline AFG1 & 4,24 & 0,09 & 0,31 \\
\hline AFG2 & 4,04 & 0,09 & 0,30 \\
\hline DON & 3,19 & 2,22 & 7,40 \\
\hline ZON & 9,06 & 0,51 & 1,70 \\
\hline
\end{tabular}

LOD: Tespit limiti LOQ: Tayin limiti RSD: Tekrarlana bilirlik

Tablo 2. Stok konsantrasyonlar [ppb]

\begin{tabular}{|l|l|l|l|l|l|l|}
\hline $\begin{array}{l}\text { Stok } \\
\text { no }\end{array}$ & AFB1 & AFB2 & AFG1 & AFG2 & DON & ZON \\
\hline 1 & 20 & 20 & 20 & 20 & 2000 & 200 \\
\hline 2 & 10 & 10 & 10 & 10 & 1000 & 100 \\
\hline 3 & 5 & 5 & 5 & 5 & 500 & 50 \\
\hline 4 & 1 & 1 & 1 & 1 & 100 & 10 \\
\hline
\end{tabular}

Tablo 3. Matris etkili standart konsantrasyonlar [ppb]

\begin{tabular}{|l|l|l|l|l|l|l|}
\hline $\begin{array}{l}\text { Mikotoksin } \\
\text { tipi }\end{array}$ & $\begin{array}{l}\text { Seviye } \\
\mathbf{1}\end{array}$ & $\begin{array}{l}\text { Seviye } \\
\mathbf{2}\end{array}$ & $\begin{array}{l}\text { Seviye } \\
\mathbf{3}\end{array}$ & $\begin{array}{l}\text { Seviye } \\
\mathbf{4}\end{array}$ & $\begin{array}{l}\text { Seviye } \\
\mathbf{5}\end{array}$ & $\begin{array}{l}\text { Seviye } \\
\mathbf{6}\end{array}$ \\
\hline AFB1 & 0,05 & 0,125 & 0,25 & 0,5 & 0,75 & 1 \\
\hline AFB2 & 0,05 & 0,125 & 0,25 & 0,5 & 0,75 & 1 \\
\hline AFG1 & 0,05 & 0,125 & 0,25 & 0,5 & 0,75 & 1 \\
\hline AFG2 & 0,05 & 0,125 & 0,25 & 0,5 & 0,75 & 1 \\
\hline DON & 5 & 12,5 & 25 & 50 & 75 & 100 \\
\hline ZON & 0,5 & 1,25 & 1,25 & 5 & 7,5 & 10 \\
\hline
\end{tabular}

\section{BULGULAR VE TARTIŞMA}

Yaptığımız çalışmada tam buğday ununda 1. 101 - 4,2. $10^{3} \mathrm{kob} \mathrm{g}^{-1}$ [ortalama $8,75.10^{2} \mathrm{kob} \mathrm{g}^{-1}$ ], beyaz unda $3.10^{1}$ $-8,7$. $10^{3} \mathrm{kob} \mathrm{g}^{-1}$ [ortalama $1,03.10^{3} \mathrm{kob} \mathrm{g}^{-1}$ ], çavdar ununda $1,310^{2}-4,3.10^{3} \mathrm{kob} \mathrm{g}^{-1}$ [ortalama $1,11.10^{3} \mathrm{kob}$ $\mathrm{g}^{-1}$ ], kepekte $5 \cdot 10^{1}-6 \cdot 10^{3} \mathrm{kob} \mathrm{g}^{-1}$ [ortalama 1,25. $10^{3}$ kob g ${ }^{-1}$ ] aralığında küf saptanmıştır. Bütün örneklerdeki küf sayısı TGK Mikrobiyolojik Kriterler Tebliği'nde [14] öngörülen maksimum sınır değerinin [ $\left[\begin{array}{ll}10^{4} & \mathrm{kob} \mathrm{g}^{-1}\end{array}\right]$ altında bulunmuştur. Aydın ve ark. [4]'nın 2009 yılında yaptıkları çalışmada 142 tane beyaz un örneklerinde $7,4 \cdot 10^{1}-1.10^{4} \mathrm{kob} \mathrm{g}^{-1}$ arasinda, Potus et al. [16] 1989 yılındaki yaptıkları çalışmada 263 tane beyaz un örneklerinde $1.10^{4}-3.10^{4} \mathrm{kob} \mathrm{g}^{-1}$, Karagözlü ve ark. [17]'nın 2000 yılındaki araştırmasında 20 mısır ununda $2.10-3.10^{5} \mathrm{kob} \mathrm{g}^{-1}$ arasında küf sayısı tespit etmişlerdir. Çalışmamızda tespit edilen küf sayıları bildirilen çalışmalardaki $[4,16,17]$ değerlerden daha düşük bulunmuştur.
Çalışmamızda incelediğimiz 112 farklı tahıl unu örneğinin 9 tanesinde aflatoksin varlığı Tablo 4'deki gibi belirlenmiştir $\left[0,17-5,95 \mu \mathrm{g} \mathrm{kg}^{-1}\right]$. Örneklerin sadece 1 [çavdar unu tanesinde toplam aflatoksin $[\mathrm{B} 1+\mathrm{B} 2+\mathrm{G} 1+\mathrm{G} 2]$ düzeyi $5,95 \mu \mathrm{g} \quad \mathrm{kg}^{-1}$ ile TGK Bulaşanlar Yönetmeliği maksimum sınır değerin $[4 \mu \mathrm{g}$ $\mathrm{kg}^{-1}$ ] üzerinde bulunmuştur [18].

Tablo 4. Tahil unlarında saptanan toplam aflatoksin $[\mathrm{B} 1+\mathrm{B} 2+\mathrm{G} 1+\mathrm{G} 2]$ miktarları $\left[\mu \mathrm{g} \mathrm{kg}^{-1}\right]$

\begin{tabular}{|c|c|c|c|c|}
\hline Örnek & $\begin{array}{l}\text { Örnek } \\
\text { sayısı }\end{array}$ & $\begin{array}{l}\text { Pozitif } \\
\text { örnek } \\
\text { sayısı }\end{array}$ & $\begin{array}{l}\text { Toplam } \\
\text { aflatoksin değer } \\
\text { aralığı } \\
{\left[\mu \mathrm{gg}^{-1}\right]}\end{array}$ & $\begin{array}{l}\text { TGK } \\
\text { Maksimum } \\
\text { Limiti [ } \mu \mathrm{g} \\
\left.\mathrm{kg}^{-1}\right]\end{array}$ \\
\hline $\begin{array}{l}\text { Tam } \\
\text { buğday } \\
\text { unu }\end{array}$ & 25 & 1 & 0,53 & \multirow{4}{*}{4} \\
\hline $\begin{array}{l}\text { Beyaz } \\
\text { un }\end{array}$ & 29 & - & - & \\
\hline $\begin{array}{l}\text { Çavdar } \\
\text { unu }\end{array}$ & 30 & 6 & $0,17-5,95$ & \\
\hline Kepek & 28 & 2 & $0,23-0,32$ & \\
\hline
\end{tabular}

Baydar ve ark. [19]'nın 2005 yılında Ankara'da yaptıkları çalışmada 25 öğütülmüş örnekte (tohum, bakliyat, tahıl unu ve nişasta) aflatoksin düzeyi HPLC yöntemi ile araştırılmıştır. Toplam aflatoksin miktarı 0,03-3,16 $\mu \mathrm{g} \mathrm{kg} \mathrm{kg}^{-1}$ arasında ölçülmüştür. Örneklerin 16'sinda AFB1 0,03-1,61 $\mu \mathrm{g} \mathrm{kg}^{-1}, 15$ 'inde AFB2 0,03$0,18 \mu \mathrm{g} \mathrm{kg}^{-1}, 18$ 'inde AFG1 0,03-2,79 $\mu \mathrm{g} \mathrm{kg}^{-1}, 19$ 'unda AFG2 0,03-0,15 $\mu \mathrm{g} \mathrm{kg} \mathrm{kg}^{-1}$ seviyeleri arasında tespit etmişlerdir. Erzurum'da 2007 yılında yapılan başka bir çalışmada 50 buğday unu örneğinde toplam aflatoksin miktarı ELISA tekniği kullanılarak araștırılmıştır [20]. Örneklerin 37 tanesinde toplam aflatoksin miktarı ölçülebilir sınır değerinden $\left[1,75 \mu \mathrm{g} \mathrm{kg}^{-1}\right]$ daha fazla bulunmuş ve örneklerin 9 'unda TGK'ne göre kabul edilebilir sınırların [4 $\mu \mathrm{g} \quad \mathrm{kg}^{-1}$ ] üzerinde olduğu saptanmıştır. Aydın ve ark. [21]'nın 2008 yılında Trakya'nın yedi farklı üretim bölgesinden temin edilen 100 buğday unu örneğinin 45'inde seviyesi $0,05-14,01$ $\mu \mathrm{g} \mathrm{kg}^{-1}$ arasında değişen aflatoksin içerdiği saptanmıştır. Örneklerin 2 tanesindeki miktar maksimum tolere edilebilir sınırların [4 $\mu \mathrm{g} \mathrm{kg}^{-1}$ ] üzerinde bulunmuştur. İran'da yapılan bir araştırmada yaz ve kış mevsimlerinde temin edilen toplam 200 tane buğday unu örneği aflatoksin varlığı açısından incelenmiştir. Kış mevsiminde toplanan 100 tane buğday unu örneğinde ortalama $0,99 \mathrm{ng} \mathrm{g}^{-1}$, yaz mevsiminde toplanan 100 tane buğday unu örneğinde ortalama $0,82 \mathrm{ng} \mathrm{g}^{-1}$ toplam aflatoksin içerdiği belirlenmiştir. Un örneklerindeki toplam aflatoksin düzeyi İran Standartları Enstitüsü tarafından belirlenen sınırlardan daha düşük seviyelerde tespit edilmiştir [22]. Adı geçen çalışmalarda [19-21] bildirilen miktarlar çalışmamızda saptadığımız miktarlar daha yüksektir.

Çalışmamızda incelediğimiz tahıl unlarının 41 tanesinde 0,06-70,04 $\mu \mathrm{g} \mathrm{kg}^{-1}$ seviyeleri arasında deoksinivalenol varlığ 1 tespit edilmiştir [Tablo 5]. Örneklerin tamamında deoksinivalenol miktarı TGK Bulaşanlar 
Yönetmeliği'nde bildirilen maksimum sınır değerin [750 $\mu \mathrm{g} \mathrm{kg}^{-1}$ ] altında bulunmuştur [18].

Tablo 5. Tahıl unlarında saptanan toplam deoksinivalenol miktarları $\left[\mu \mathrm{g} \mathrm{kg}^{-1}\right]$

\begin{tabular}{|c|c|c|c|c|}
\hline Örnek & $\begin{array}{l}\text { Örnek } \\
\text { sayısı }\end{array}$ & $\begin{array}{l}\text { Pozitif } \\
\text { örnek } \\
\text { sayısı }\end{array}$ & $\begin{array}{l}\text { Deoksinivalenol } \\
\text { değer aralığı } \\
{\left[\mu \mathrm{g} \mathrm{kg}^{-1}\right]}\end{array}$ & $\begin{array}{l}\text { TGK } \\
\text { Maksimum } \\
\text { Limiti [ [ } \mathrm{gg} \\
\left.\mathrm{kg}^{-1}\right]\end{array}$ \\
\hline $\begin{array}{l}\text { Tam } \\
\text { buğday } \\
\text { unu }\end{array}$ & 25 & 7 & $0,07-70,04$ & 750 \\
\hline $\begin{array}{l}\text { Beyaz } \\
\text { un }\end{array}$ & 29 & 18 & $0.06-19,6$ & \\
\hline $\begin{array}{l}\text { Çavdar } \\
\text { unu }\end{array}$ & 30 & 5 & $0,07-25,0$ & \\
\hline Kepek & 28 & 11 & $0,06-17,64$ & \\
\hline
\end{tabular}

Bakırcı [23]'nın 2014 yılında yaptığı çalışmada toplam 381 tane tahıl ve tahıl bazlı örneklerde HPLC yöntemi kullanılarak DON miktarlarını araştırmıştır. Bu çalışmada 144 örneğin 13 tanesinde 132,4-9589,4 $\mu \mathrm{g} \mathrm{kg}^{-}$ 1 aralığında DON ölçülmüştür. Valcheva et al. [24] tarafından 2003-2005 yılları arasında yapılan çalışmada 103 buğday örneğinde TLC [ince tabaka kromatografisi] yöntemi kullanılarak DON seviyeleri araştırılmıştır. 2003 y1lında incelenen örneklerin 17'sinde DON 200$2000 \mu \mathrm{g} \mathrm{kg}^{-1}, 2004$ y1lında incelenen örneklerin 21'inde 200-2500 $\mu \mathrm{g} \mathrm{kg}$, 2005 y1lında incelenen örneklerin 7'sinde 200-1000 $\mu \mathrm{g} \mathrm{kg}^{-1}$, ortalama 450-884 $\mathrm{\mu g} \mathrm{kg}^{-1}$ arasında DON tespit etmişlerdir. Danimarka'da toplam 190 tane tahıl unlarında [buğday, durum buğdayı ve çavdar] DON düzeyi araştırılmıştır [25]. Araştırmada 1998-2000 yılları arası hasat döneminde 14 adet buğday ununda 20-527 [ortalama 191] $\mu \mathrm{g} \mathrm{kg}^{-1}$ aralığında, 16 adet çavdar ununda 20-257 [ortalama 99] $\mu \mathrm{g} \mathrm{kg}^{-1}$ aralığında DON miktarı belirlenmiştir. Çalışmanın 2000-2001 yılları arası hasat döneminde 133 örnekten fazlasında $500 \mu \mathrm{g} \mathrm{kg}^{-1}$ a ulaşan düzeylerde DON belirlenmiştir. Örneklerde saptanan en yüksek DON düzeyi $2591 \mu \mathrm{g} \mathrm{kg}$ ${ }^{1}$,dır. Romanya'da 2014 y1l hasat mevsimi boyunca 31 tane bütün işlenmemiş buğday ve 35 tane buğday unu DON yönünden araştırılmıştır. Çalışmada 31 buğday örneğinin sekizinde $110-1787 \mu \mathrm{g} \mathrm{kg}^{-1}$, buğday unu örneklerinin bir tanesinde $190 \mu \mathrm{g} \mathrm{kg}^{-1}$ düzeylerinde DON tespit edilmiştir [26]. Ontario çiftliklerinden temin edilen 100 tane tahıl numunesinde DON varlığı araştırılmıştır. Araştırmada 25 tane kışlık buğdayın tümünde 1,044-982 $\mathrm{ng} \mathrm{g}^{-1}$, on beş tane baharlık buğdayın hepsinde 1,207-122 $\mathrm{ng} \mathrm{g}^{-1}$, misır örneklerinin 14'ünde 1,041-989 $\mathrm{ng} \mathrm{g}^{-1}$, yulaf örneklerinin 6'sında 22-71 $\mathrm{ng} \mathrm{g}^{-1}$, yirmi tane arpa

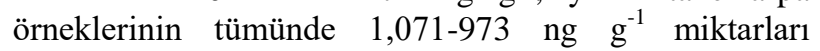
arasında DON saptanmıştır [27]. Araştırmamızda elde edilen DON [0,06-70,04 $\mu \mathrm{g} \mathrm{kg}^{-1}$ ] miktarları Bakırc1 [23], Valcheva [24], Rasmussen [25], Stanciu [26] ve Martos [27] tarafından bildirilenlerden daha düşük bulunmuştur.

Deoksinivalenol tahıllarda sıklıkla rastlanan B grubuna dahil bir trikotesendir. $\mathrm{Bu}$ mikotoksini üreten başlıca türler $F$. graminearum ve $F$. culmorum'dur [28]. $F$. graminearum'un gelişme şartlarında optimum sicaklık $24-26^{\circ} \mathrm{C}$ ve minimum su aktivitesi 0,90 'dır. Bu küf türü DON'un yanisira nivalenol ve ZON'da oluşturabilmektedir [29]. Araştırmamızda DON kontaminasyonuna rastlanılan tahıl unu çeşitlerinde aynı zamanda ZON varlığ 1 da tespit edilmiştir [Tablo 5 ve 6].

Çalışmamızda incelediğimiz tahıl unlarının 15 tanesinde 0,04-3,04 $\mu \mathrm{g} \mathrm{kg}^{-1}$ arasında değişen düzeylerde zearalanon içerdiği Tablo 6'daki gibi bulunmuştur. Saptanan değerlerler TGK Bulaşanlar Yönetmeliği'nde öngörülen maksimum tolere edilebilir sınırlarının [75 $\mu \mathrm{g}$ $\mathrm{kg}^{-1}$ ] çok altındadır [18].

Tablo 6. Tahıl unlarında saptanan toplam zearalanon miktarları $\left[\mu \mathrm{g} \mathrm{kg}^{-1}\right]$

\begin{tabular}{|l|l|l|l|l|}
\hline Örnek & $\begin{array}{l}\text { Örnek } \\
\text { sayısı }\end{array}$ & $\begin{array}{l}\text { Pozitif } \\
\text { örnek } \\
\text { sayısı }\end{array}$ & $\begin{array}{l}\text { Zearalanon } \\
\text { değer aralığı } \\
{\left[\boldsymbol{\mu g} \mathbf{~ k g}^{-1}\right]}\end{array}$ & $\begin{array}{l}\text { TGK } \\
\text { maksimum } \\
\text { limiti }[\boldsymbol{\mu g} \\
\left.\mathbf{k g}^{-1}\right]\end{array}$ \\
\hline $\begin{array}{l}\text { Tam } \\
\text { buğday } \\
\text { unu }\end{array}$ & 25 & 3 & $0,04-2,43$ & \\
\cline { 1 - 2 } $\begin{array}{l}\text { Beyaz } \\
\text { un }\end{array}$ & 29 & 6 & $0,4-3,04$ & \\
\cline { 1 - 2 } $\begin{array}{l}\text { Çavdar } \\
\text { unu }\end{array}$ & 30 & 5 & $0,11-0,48$ & \\
\cline { 1 - 4 } Kepek & 28 & 1 & 2,77 & \\
\hline
\end{tabular}

Bakırcı [23]'nın 2014 yılındaki araştırmasında HPLC yöntemi kullanılarak tahıl ve tahıl bazlı örneklerin 8 tanesinde ZON seviyesi $25-74 \mu \mathrm{g} \mathrm{kg}^{-1}$ aralığında bulunmuştur. Valcheva et al. [24] 2003-2005 y1lları arasında toplam 103 buğday örneğinde TLC [ince tabaka kromatografisi] yöntemi kullanılarak ZON seviyelerini araştırmışlardır. Araştırmada 2003 yılında 14 örnekte $300-4500 \mu \mathrm{g} \mathrm{kg}^{-1}, 2004$ y1lında 24 örnekte 90-6000 $\mu \mathrm{g}$ $\mathrm{kg}^{-1}, 2005$ yılında 6 örnekte100-1500 $\mathrm{g} \mathrm{kg} \mathrm{k}^{-1}$ düzeyleri arasında ZON tespit edilmiştir. Ayalew et al. [30] 2006 yılındaki yaptıkları çalışmada buğday, arpa ve sorgum örneklerini analiz etmişlerdir. Araştırmada $32 \mu \mathrm{g} \mathrm{kg}^{-1}$, ulaşan ZON düzeyi sadece sorgum örneklerinde tespit edilmiştir. Katar'da 2004 yılında yapılan çalışmada 106 tane çeşitli gıdalarda [tahıl ve tahıl ürünleri, fındık ve fındık ürünleri, baharatlar, kuru meyveler ve içecekler] HPLC yöntemi kullanılarak ZON açısından incelenmiştir [31]. On üç numunenin 0.18-6.81 $\mu \mathrm{g} \mathrm{kg}^{-1}$ aralığında ZON içerdiği tespit edilmiştir. Lavkor [32] Adana'da 2015-2016 yılı hasat döneminde toplam 134 misır örneğindeki ZON seviyesini araştırmıştır. Örneklerdeki ZON düzeyi 3,4-551,8 $\mu \mathrm{g} \mathrm{kg}^{-1}$ aralığında belirlemiştir. Romanya'nın güneyindeki dört farklı bölgeden temin edilen 31 tane bütün işlenmemiş buğday ve 36 tane beyaz buğday unu dahil olmak üzere 66 tane örnekte ZON varlığı araştırılmıştır. Araştırmada 31 buğday örneğinin dördünde $327-1135 \mu \mathrm{g} \mathrm{kg}^{-1}$, otuz beş buğday unu örneğinin 2'sinde $51-73 \mu \mathrm{g} \mathrm{kg}^{-1}$ seviyelerinde ZON belirlenmiştir [26]. Martos et al. 2008-2009 y1lları arasında toplanan 100 tane tahıl örneği [25 kışlık buğday, 15 baharlık buğday, 15 misır, 10 yulaf, 20 arpa, 15 çavdar] ZON kontaminasyonu açısından incelenmiştir. Çalışmada 25 tane kışlık buğdayın sekizinde 24-145 $\mathrm{ng} \mathrm{g}^{-1}$, on beş baharlık buğdayın 
10'unda 38-293 ng g ${ }^{-1}$, misır örneklerinin 9'unda 61-783 ng $\mathrm{g}^{-1}$, çavdar örneklerinin 5 tanesinde 25-39 ng g ${ }^{1}$ miktarları arasında ZON tespit edilmiştir. Yulaf ve arpa örneklerinde ZON'a rastlanmamıştır [27]. İncelediğimiz tahıl unlarındaki zearalanon seviyeleri Bakırcı [23], Valcheva [24], Stanciu [26], Martos [27], Ayalew [30], Abdulkadar [31] ve Lavkor [32] tarafindan bildirilenlerden daha düşük bulunmuştur.

\section{SONUÇ}

Çalışmamızda elde edilen bulgular İstanbul'da tüketime sunulan tahıl unlarının gıda güvenliği açısından risk teşkil etmediğine işaret etmektedir. Pozitif örneklerden biri hariç yasal limitlerin çok altında mikotoksin içeriyor olması halk sağlığı açısından sevindirici bir durumdur. Bir g1da ürününün kalitesi hem besleyici unsurları eksiksiz içermesi hem de mikrobiyolojik ve toksikolojik hijyeni ile yakından ilişkilidir. Gıda güvenliğinin sağlanmasında; iyi tarım uygulamaları [GAP], iyi üretim uygulamaları [GMP], iyi saklama uygulamaları [GSP], iyi dağıtım uygulamaları [GDP] ve HACCP gibi sistemlerin önleme faaliyetleri büyük rol oynamaktadır. $\mathrm{Bu}$ nedenle gıda güvenliğinin sağlanması için gerekli önlemlerin arttırılarak sürdürülmesi aynı zamanda gıdalarda mikotoksin kalıntılarına yönelik araştırmaların sıklıkla yapılması toplum sağlığının korunmasına yönelik temel zorunluluk olarak görülmektedir.

\section{KAYNAKLAR}

[1] Alshannaq A, Yu JH. Occurrence, toxicity, and analysis of major mycotoxins in food. International journal of environmental research and public health. 2017:14(6), 632.

[2] European Commission (EC). Green Paper from the Commission to the Council, the European Parliament, the European Economic and Social Committee and the Committee of the RegionsAdapting to climate change in Europe-Options for EU action. 2007: 849, Brussels, Belgium.EC:https://eur-

lex.europa.eu/legalcontent/EN/TXT/?uri=CELEX \%3A52007DC0354

[3] Magan N, Medina A, Aldred D. Possible climatechange effects on mycotoxin contamination of food crops pre- and postharvest. Plant Pathol. 2011: 1, 150-163.

[4] Aydın A, Paulsen P, Smulders FJM. The physicochemical and microbiological properties of wheat flour in Thrace. Turk J Agric For. 2009: 445-454.

[5] Köksal O. National nutrition-health and food consumption survey of Turkey. Unicef Ankara. 1974.

[6] Türkiye İsraf Raporu 2018, TİR:https://tuketici.ticaret.gov.tr/data/5e6b33e91 3b876e4200a0101/Turkiye_Israf_Raporu_2018.p df

[7] Miraglia M, Brera C. Mycotoxins in grains and related products. In "Food Analysis by HPLC". 2nd ed. pp. Leo. M. L. Nollet ed. Marcel 9Dekker Inc. New York, U. S. A. 2000:493-522.

[8] Abdallah M.F, Girgin G, Baydar T. Mycotoxin Detection in Maize, Commercial Feed, and Raw Dairy Milk Samples from Assiut City, Egypt. Vet. Sci. 2019: 6,57.

[9] Camlibel L. IGEME research and Developmental Presidency. Agricultural Administration. Ankara.1995.

[10] Nizam F, Oguz H. Occurrence of aflatoxins in layer feed and corn samples in Konya province. Food Addit Contam. 2003: 20, 654-658.

[11] Giray B, Girgin G, Engin AB, Aydin S, Sahin G. Aflatoxin levels in wheat samples consumed in some regions of Turkey. Food Control. 2007:18: 23-29.

[12] Midura TF, Bryant RG. Sampling plans, sample collection, shipment, and preparation for analysis. Compendium of Methods for Microbiological Examination of Foods. Washington (DC). American Public Health Association. 2001.

[13] AOAC International Official Methods of Analysis of AOAC International, 18th edn. AOAC International, Gaithersburg, USA: 2005.

[14] Magnusson B. The fitness for purpose of analytical methods: a laboratory guide to method validation and related topics. 2014.

[15] Türk Gida Kodeksi, [TGK]:https://www.resmigazete.gov.tr/eskiler/20 10/01/20100108-10.htm.

[16] Potus J, Suchet P. Les problemes de microbiologie en meunerie. Industries des Cereales. 1989: 58: 27-33.

[17] Karagözlü N, Karapınar M. Bazı Tahıl ve Ürünlerinde Okratoksin A ve Fungal Kontaminasyon. Turk J Bio. 2000: 24 561-572.

[18] Türk Gida Kodeksi, [TGK]:https://www.resmigazete.gov.tr/eskiler/20 11/12/20111229M3-8.htm

https://www.resmigazete.gov.tr/eskiler/2012/12/2 0121219-10.htm

[19] Baydar T, Engin A, Girgin G, Aydın S, Şahin G. Aflatoxın And Ochratoxın In Varıous Types Of Commonly Consumed Retall Ground Samples In Ankara, Turkey. Ann Agric Environ Med. 2005: 12, 193-197.

[20] Özturan K, Ünsal C, Karakaya Y, Atasever M, Ceylan Z, Atasever Aydemir M, Demirkaya A K. Erzurum'da Tüketime Sunulan Buğday Unlarının Toplam Aflatoksin, Aflatoksin.B1 ve Okratoksin A Yönünden İncelenmesi. Atatürk Üniversitesi Vet. Bil. Derg. 2007: 2 (4) 172-176.

[21] Aydin A, Gunsen U, Demirel S. Total aflatoxin, aflatoxin B1 and ochratoxin A levels in Turkish wheat flour. Journal of Food and Drug Analysis, 16(2). 2008.

[22] Taheri N, Semnani S, Roshandel G, Namjoo M, Keshavarzian H, Chogan AG, Joshaghani H. Aflatoxin contamination in wheat flour samples 
from Golestan Province, Northeast of Iran. Iranian journal of public health. 2012: 41(9), 42.

[23] Bakırcı G. Tahıl ve Tahıl Ürünlerinin Aflatoksin, Okratoksin A, Zearalenon, Fumonisin ve Deoksinivalenol Mikotoksinleri Yönünden İncelenmesi. Akademik G1da. 2014: 12(2): 46-56.

[24] Valcheva A, Valchev G. The Fusariotoxins Zearalenon and Deoxinivalenol as Natural Contaminators of Some Basic Cereal Components in the Production of Combined Feed. Bulgarian Journal of Agricultural Science, 13. National Centre for Agrarian Sciences. 2007:99-104

[25] Rasmussen PH, Ghorbani F, Berg T. Deoxynivalenol and other Fusarium toxins in wheat and rye flours on the Danish market. Food Additives \& Contaminants.2003: 20(4), 396-404.

[26] Stanciu O, Juan C, Miere D, Loghin F, Mañes J. Occurrence and co-occurrence of Fusarium mycotoxins in wheat grains and wheat flour from Romania. Food Control. 2017: 73, 147-155.

[27] Martos P, Thompson W, Diaz G. Multiresidue mycotoxin analysis in wheat, barley, oats, rye and maize grain by high-performance liquid chromatography-tandem mass spectrometry. World Mycotoxin Journal. 2010: 3(3), 205-223.

[28] Bretz M, Beyer M, Cramer B, Knecht A, Humpf HU. Thermal degradation of the Fusarium mycotoxin deoxynivalenol, J Agric Food Chem. 2006: 54(17), 6445-51.

[29] Sweeney MJ, Dobson ADW. Mycotoxin production by Aspergillus, Fusarium and Penicillium species, Int J Food Microbiol. 1998: 43, 141-158.

[30] Ayalew A, Fehrmann H, Lepschy J, Beck R, Abate D. Natural occurence of mycotoxins in staple cereals from Ethiophia. Mycopathologia. 2006: 162: 5763.

[31] Abdulkadar AHW, Al-Ali AA, Al-Kildi AM, Al Jedah JH. Mycotoxins in food products available in Qatar. Food Control. 2004: 15: 543-548.

[32] Lavkor I. Misırda Koçan Çürüklüğüne Neden Olan Fungal Türler ve Misırda Oluşan Mikotoksinler. The Journal Of Food. 2019: 44 (6): 1197-1209. 